\title{
Isolasi Senyawa Flavonoid dari Tumbuhan Cocor Bebek Sebagai Sediaan Inhibitor Korosi
}

\author{
Tri Reksa Saputra ${ }^{* a}$, Esti Purnamasari ${ }^{a}$, Anderson Arnold Aloanis ${ }^{b}$ \\ a Teknik Kimia, Politeknik Negeri Bandung, Bandung,40012, Indonesia \\ ${ }^{b}$ Kimia, Universitas Negeri Manado, Tondano, 95619, Indonesia
}

\begin{tabular}{l} 
I N F O A R T I K E L \\
\hline Diterima 29 September 2019 \\
Disetujui 27 Oktober 2019 \\
\\
\hline Key word: \\
Crassulaceae, \\
Kalanchoe pinnata, \\
Flavonol \\
\hline Kata kunci: \\
Crassulaceae, \\
Kalanchoe pinnata, \\
Flavonol
\end{tabular}

${ }^{*}$ e-mail: tri.reksa@polban.ac.id

*Telp: +62179294177

\begin{abstract}
A B S T R A T
Various species of Kalanchoe plant has been widely used for traditional medicine and also as an ornamental plant. This research is a continuing search for secondary metabolites from Kalanchoe plants in Indonesia. The fresh leaves of Kalanchoe pinnata $(6 \mathrm{~kg})$ was extracted at room temperature with methanol to obtain a concentrated extract. The concentrated extract of methanol was further partitioned successively with n-hexane and ethyl acetate. Yellow solid of pure isolates from ethyl acetate extract was separated by various chromatographic techniques. The chemical structure of isolates was determined by spectroscopic analysis of $U V, I R, M S,{ }^{1} \mathrm{H}-\mathrm{NMR},{ }^{13} \mathrm{C}-$ $N M R$ data and a comparison wih those previously reported on literature and identified as a flavonoid compound 3,3',4',5,7 pentahydroxyiflavone also known as kuersetin which belong to the flavonol class.
\end{abstract}

\section{A B STRAK}

Berbagai spesies tanaman Kalanchoe telah digunakan secara luas untuk bahan baku obat tradisional dan juga sebagai tanaman hias. Penelitian ini merupakan penelitian lanjutan dari pencarian senyawa metabolit sekunder dari tumbuhan Kalanchoe Indonesia. Daun segar Kalanchoe pinnata sebanyak 6 $\mathrm{kg}$ diekstraksi dengan metanol pada temperatur kamar sehingga diperoleh ekstrak pekat metanol. Ekstrak pekat metanol selanjutnya dipartisi berturutturut dengan $n$-heksana dan etil asetat. Ekstrak semipolar kemudian dilakukan isolasi senyawa flavonoid dan dihasilkan isolat berwarna kuning melalui berbagai teknik kromatografi. Struktur kimia isolat ditentukan berdasarkan hasil analisis spektroskopi UV, IR, MS, ${ }^{1} \mathrm{H}-\mathrm{NMR},{ }^{13} \mathrm{C}-\mathrm{NMR}$ serta perbadingan data spektroskopi yang diperoleh dari literatur dan diidentifikasi sebagai senyawa flavonoid yaitu 3,3', $4^{\prime}, 5,7$ pentahidroksiflavon atau kuersetin.

\section{Pendahuluan}

Banyak sekali bahan-bahan alam yang terdapat di lingkungan sekitar, diantaranya tumbuhan, hewan, dan mikroorganisme, namun yang paling banyak digunakan oleh masyarakat luas yaitu tumbuhan, hal ini yang mendasari banyak penelitian yang dilakukan untuk mengeksplorasi senyawa-senyawa dari tumbuhan terutama senyawa metabolit sekunder. Senyawa metabolit sekunder dapat berfungsi sebagai senyawa racun untuk pertahanan, zat atraktan terhadap sesama jenisnya, atau sebagai zat pewarna untuk menarik spesies lain [1]. Dengan demikian, berbagai produk metabolit sekunder berpotensi untuk dimanfaatkan sebagai obat, insektisida alami, material sains, dan berbagai kepentingan industri [2]. Senyawa-senyawa metabolit sekunder inilah yang biasanya dimanfaatkan sebagai sumber kajian bagi penelitianpenelitian lebih lanjut baik itu dalam bidang industri yang ramah lingkungan maupun sebagai bahan obat-obatan. Penggunaan senyawa-senyawa bahan alam pada umumnya 
hanya digunakan sebagai simplisia atau senyawa model dalam sintesis obat-obatan, namun tidak menutup kemungkinan digunakan dalam bidang lain seperti halnya aplikasi untuk inhibitor korosi. Inhibitor korosi sendiri didefinisikan sebagai suatu zat yang apabila ditambahkan dalam jumlah sedikit ke dalam lingkungan akan menurunkan serangan korosi lingkungan terhadap logam. Umumnya inhibitor korosi berasal dari senyawa-senyawa organik dan anorganik yang mengandung gugus-gugus yang memiliki pasangan elektron bebas, seperti nitrit, kromat, fosfat, urea, fenilalanin, imidazolin, dan senyawa-senyawa amina. Tidak dapat dipungkiri bahwa bahan kimia sintesis ini merupakan bahan kimia yang berbahaya, harganya lumayan mahal, dan tidak ramah lingkungan, maka sering industriindustri kecil dan menengah jarang menggunakan inhibitor pada sistem pendingin, sistem pemipaan, dan sistem pengolahan air produksi mereka, untuk melindungi besi/baja dari serangan korosi. Untuk itu penggunaan inhibitor yang aman, mudah didapatkan, bersifat biodegradable, biaya murah, dan ramah lingkungan sangatlah diperlukan. Salah satunya adalah dengan menggunakan senyawa-senyawa organik yang berasal dari ekstrak bahan alam. Salah satu senyawa metabolit sekunder yang paling banyak diketahui adalah flavonoid yang dikenal oleh masyarakat luas sebagai senyawa yang berpotensi sebagai antioksidan.

Salah satu tumbuhan yang diketahui banyak mengandung senyawa-senyawa aktif yaitu tumbuhan Cocor Bebek (Kalanchoe pinnata). Tumbuhan $K$. pinnata merupakan tumbuhan yang mempunyai peran penting pada pengobatan tradisional. Dari tumbuhan $K$. pinnata telah ditemukan aktivitas farmakologi yang beragam seperti antiparasit, penambah sistem imun, penyembuhan luka, melindungi hati dari kerusakan, antisembelit, antiinflamasi, antidiabetes, antioksidan, antimikroba, analgesik, penyembuhan epilepsi, penurun panas, dan antipiretik [3]. Mengingat aktifitas yang dimiliki oleh tumbuhan $K$. pinnata maka tumbuhan ini banyak diteliti sehingga banyak dihasilkan senyawa-senyawa senyawa metabolit sekunder baik dari golongan steroid, alkaloid, tanin, saponin, flavonoid maupun senyawa gula.

Penelitian ini merupakan penelitian lanjutan dari penelitian-penelitian sebelumnya, dimana pada tahun 2016, Saputra dan Ngatin melakukan penelitian mengenai skrining ekstrak dari tumbuhan K.pinnata sebagai inhibitor korosi dimana hasil dari penelitian tersebut ekstrak semipolar (ekstrak etil asetat) mampu menurunkan laju korosi baja karbon dalam larutan $\mathrm{NaCl}$ 3,5\% dari 2,954 mpy menjadi 0,963 mpy dengan penambahan 500 ppm ekstrak, dan 0,923 mpy pada penambahan 1000 ppm. Pada tahun 2017, Saputra dan Ngatin kembali meneliti mengenai pengelompokan golongan senyawa ekstrak semi polar daun Cocor bebek (Kalanchoe pinnata) dan aktivitasnya sebagai inhibitor korosi, dimana penelitian ini dilakukan untuk mengelompokkan senyawa-senyawa semipolar dari tumbuhan K.pinnata dan didapatkan hasil 2 kelompok ekstrak, dimana kedua kelompok tersebut termasuk ke dalam senyawa-senyawa golongan Flavonoid. Kelompok senyawa pertama mampu menurunkan laju korosi baja karbon dalam larutan $\mathrm{NaCl} 3,5 \%$ dari 0,0437 mmpy menjadi 0,0378 mmpy dengan penambahan 1000 ppm pada waktu pengkorosian selama 168 jam, sedangkan kelompok senyawa kedua menurunkan laju korosi baja karbon dalam larutan $\mathrm{NaCl} 3,5 \%$ dari 0,0437 mmpy menjadi 0,0401 mmpy. Pada tahun 2018, Ngatin dan Saputra melakukan penelitian mengenai pemanfaatan ekstrak daun Cocor Bebek sebagai inhibitor korosi baja karbon di lingkungan asam klorida yang dihasilkan ekstrak daun cocor bebek menggunakan pelarutan aseton menghasilkan kadar antioksidan tertinggi yaitu 235,10 ppm dibandingkan pelarut $n$-heksana, etil asetat, metanol, dan asam asetat dan mampu menurunkan laju korosi sebesar 17,22 mpy dengan efisiensi inhibitor 34,47 \%. Merujuk penelitian-penelitian ini, maka akan dilakukan penelitian mengenai isolasi senyawa-senyawa flavonoid dari tumbuhan K.pinnata dimana dari hasil penelitian-penelitian sebelumnya didapatkan hasil bahwa ekstrak semipolar yang mengandung senyawa-senyawa flavonoid berpotensi sebagai inhibitor korosi.

\section{Bahan dan Metode}


Daun tumbuhan Kalanchoe pinnata dikumpulkan dari daerah Padalarang, Bandung Barat, Jawa Barat, Indonesia. Bahan kimia yang digunakan terdiri dari berbagai jenis pelarut teknis (didestilasi ulang) seperti; $n$ heksana, metanol, aseton, dan pro-analis seperti; diklorometan dan kloroform. Silika $\mathrm{GF}_{254}$ untuk KLT (kromatografi lapis tipis), Silika G60 (10-40 $\mu \mathrm{m})$ dan luas permukaan (500 $\mathrm{m}^{2} / \mathrm{g}$ ) untuk Kromatografi cair vakum dan silika G60 (70-230 dan 230-400 mesh) untuk kromatografi kolom terbuka, serta pereaksi penampak noda $\mathrm{AlCl}_{3}$ 10\% dalam etanol.

Peralatan yang digunakan meliputi alat gelas yang umum digunakan di laboratorium kimia organik, maserator, rotary evaporator R200 Buchi dengan pompa vakum Vac V-500 Buchi dan penangas air B-490 Buchi, kolom kromatografi terbuka berbagai ukuran, lampu UV Vilbert Luomart ( $\lambda 254 \mathrm{~nm}$ dan $\lambda 365 \mathrm{~nm}$ ), spektrofotometer FTIR Spectrum One Perkin Elmer, Spektrometer Nuclear Magnetic Resonance (NMR) JEOL JNM ECA-500 dengan TMS sebagai standard dalam.

\section{Ekstraksi dan isolasi}

Daun segar K. pinnata sebanyak 5,7 kg dihaluskan kemudian diekstraksi dan dipekatkan. Ekstrak metanol yang diperoleh sebanyak 155,74 g kemudian dilarutkan dengan air dan dipartisi berturut-turut dengan nheksana dan etil asetat sehingga diperoleh ekstrak n-heksan $(23,4 \mathrm{~g})$ dan ekstrak etil asetat (15 g). Ekstrak etil asetat kemudian dilakukan pemisahan dengan menggunakan kromatografi vakum cair yang menghasilkan 7 fraksi gabungan. Penggabungan fraksi tersebut dilakukan dengan panduan kromatografi lapis tipis dan dibawah lampu UV $254 \mathrm{~nm}$ serta pereaksi penampak $\mathrm{AlCl}_{3}$ 10\% dalam etanol. Dari 7 fraksi gabungan tersebut, fraksi 3 dan fraksi 4 dilakukan pemisahan lebih lanjut. Fraksi 3 dilakukan pemurnian dengan menggunakan kromatografi kolom dengan menggunakan silika G60 dengan menggunakan eluen $n$-heksana:etil asetat (3:7) secara isokratik yang kemudian menghasilkan padatan berwarna kuning sebanyak 95,5 mg yang kemudian dilakukan pemisahan kembali dengan menggunakan kromatografi kolom dengan menggunakan silika ODS dengan eluen metanol : air : aseton ( 1:2:1) secara isokratik dan menghasilkan isolat berupa padatan kuning sebanyak 7,1 mg.

Fraksi 4 dilakukan pemisahan dengan metode kromatografi kolom dengan menggunakan silika G60 dengan eluen nheksana : etil asetat (3:7) secara isokratik yang dihasilkan padatan berwarna kuning yang selanjutnya dilakukan proses pemurnian dengan menggunakan metode KLT preparatif dengan menggunakan eluen $n$-heksana : etil asetat (4:6) sehingga diperoleh isolat berupa padatan berwarna kuning sebanyak 5,2 mg.

\section{Hasil dan Pembahasan}

Ekstrak metanol dari daun segar $K$. pinnata dipekatkan dan dilarutkan ke dalam air. Lapisan air selanjutnya dipartisi berurut-turut antara $n$-heksana dan etil asetat. Ekstrak etil asetat kemudian dipisahkan dengan berbagai metode kromatografi dan diperoleh isolat sebanyak (11 mg) berupa padatan berwarna kuning.

Isolat diperoleh sebagai kristal kuning; UV (MeOH) $\lambda_{\text {maks }}$ : 255,4; 370,8, 268,4; 340,0 nm; IR (KBr) vmaks: $3400(\mathrm{OH}), 2000-1750$ (overtone aromatik), 1650 (C=O keton), 1600, 1500, 1400 (turunan benzen), 1092 (C-O eter), $800-750 \mathrm{~cm}^{-1}$ (disubtitusi benzen) ; ${ }^{1} \mathrm{H}-\mathrm{NMR}$ (Aseton, 500,0 MHz) $\delta$ ppm: 6,23 (1H, d, J=1,95 Hz, H-6), 6,49 $(1 \mathrm{H}, \mathrm{d}, J=1,95 \mathrm{~Hz}, \mathrm{H}-8), 6,97(1 \mathrm{H}, \mathrm{d}, J=8,45 \mathrm{~Hz}$, H-5'), 7,79 (1H, d, J = 1,95 Hz, H-2'), 7,79 (1H, d, $J=1,95$ dan 8,45Hz, H-6'); ${ }^{13} \mathrm{C}-\mathrm{NMR}$ (Aseton-D6, 125,76 MHz) $\delta$ ppm: 164,9 (C-2), 136,7 (C-3), 176,5 (C-4), 164,9 (C-5), 99,1 (C-6), 164,9 (C-7), 94,5 (C-8), 157,8 (C-9), 104,1 (C-10), 123,7 (C-1'), 115,7 (C-2'), 145,8 (C-3'), 148,3 (C-4'), 116, 2 (C$\left.5^{\prime}\right), 121,5\left(\mathrm{C}-6^{\prime}\right)$; ESIMS $m / z[\mathrm{M}-1]^{+301,43,[\mathrm{M}]^{+}}$ 302,43 .

Data UV memperlihatkan hasil serapan pada daerah $\lambda_{\text {maks }} 370,8 \mathrm{~nm}$ (pita 1) dan $255,4 \mathrm{~nm}$ (pita 2) yang merupakan serapan khas senyawa flavonoid. Hal ini mengindikasikan pada pita 1 menunjukkan serapan yang berhubungan dengan resonansi gugus sinamoil yang melibatkan cincin B dan pita 2 menunjukkan serapan yang berhubungan dengan resonansi gugus benzoil yang melibatkan cincin A dari flavonoid. Dengan penambahan pereaksi geser $\mathrm{AlCl}_{3}$ serapan maksimum pita 1 menjadi 340,0 $\mathrm{nm}$, dan pita 2 menjadi 268,4 terjadi pergeseran 
batokromik disertai penurunan intensitas pada pita 1, penurunan intensitas pada pita 1 disebabkan karena terbentuknya khelat antara $\mathrm{AlCl}_{3}$ dengan cincin $\mathrm{B}$.

Dari data IR serapan berupa pita lebar pada bilangan gelombang $3400 \mathrm{~cm}^{-1}$ yang menunjukkan ada gugus hidroksil (regang O$\mathrm{H}), 2000-1750 \mathrm{~cm}^{-1}$ (overtone aromatik), $1650 \mathrm{~cm}^{-}$ ${ }^{1}$ (regang $\mathrm{C}=\mathrm{O}$ karbonil), $1600-1400 \mathrm{~cm}^{-1}$ (regang $\mathrm{C}=\mathrm{C}$ aromatik), $1092 \mathrm{~cm}^{-1}$ (Regang $\mathrm{C}-\mathrm{O}$ eter) dan $800-750 \mathrm{~cm}^{-1}$ (disubtitusi benzen).

Data ${ }^{13} \mathrm{C}-\mathrm{NMR}$, Isolat memiliki 15 sinyal karbon yang terdiri dari satu karbonil pada $\delta c$ 176,55 ppm, 12 atom karbon aromatik yang muncul pada rentang sinyal antara $\delta c 100-160$ ppm dan dua atom karbon aromatik yang shielded yang muncul pada sinyal $\delta c 94,48$ ppm dan 99.09 ppm karena bertetangga dengan gugus karbon yang terikat oleh gugus hidroksil.

Data ${ }^{1} \mathrm{H}-\mathrm{NMR}$ pada senyawa 1 terdiri dari lima proton yang terikat pada $\mathrm{Csp}^{2}$ dimana dapat dihitung $J$ atau tetapan penjodohan dapat dilihat bahwa pada H6 dan H8 berposisi meta karena mempunyai $J$ yang sama yaitu 1,95. Posisi $\mathrm{H} 2^{\prime}$ dan $\mathrm{H}^{\prime}$ juga saling berposisi meta karena memiliki harga $J$ yang sama yaitu 1,95 , sedangkan pada posisi $\mathrm{H}^{\prime}$ ' berposisi orto terhadap $\mathrm{H}^{\prime}{ }^{\prime}$ karena memiliki harga $J=8,45$ yang merupakan pengarah orto dalam sistem aromatik.

Isolat kemudian dilakukan pengukuran MS untuk mengetahui berat molekulnya. Dari data MS menggunakan metode ion negatif dihasilkan [m/z [M+H]-] sebesar 301,04 yang berarti berat molekul yang sebenarnya adalah 302,04 .

Dari data UV, IR, NMR dan MS maka diduga Isolat memiliki rumus molekul $\mathrm{C}_{15} \mathrm{H}_{10} \mathrm{O}_{7}$. Mengetahui dugaan rumus molekul tersebut, maka dapat diperoleh nilai DBE 11 yang terdiri dari 8 ikatan rangkap dan 3 siklik. Dugaan struktur Isolat adalah $3,3^{\prime}, 4^{\prime}, 5^{\prime} 7$ pentahidroksiflavon atau lebih dikenal dengan Kuersetin.

\section{Kesimpulan}

Berdasarkan hasil penelitian terhadap ekstrak etil asetat daun $K$. pinnata diperoleh senyawa hasil isolasi golongan flavonoid berbentuk padatan kuning yaitu 3,3', $4^{\prime}, 5,7$ pentahidroksiflavon atau kuersetin.

\section{Daftar Pustaka}

1. Dewick, P.M., Medicinal Natural Products: A Biosynthetic Approach. Second edition. London, John Wiley and sons. 2009.

2. Harbourne, J.B., Metode Fitokimia: Penuntun Cara Menganalisis Tumbuhan Terbitan Kedua. Bandung. Penerbit ITB. 1987.

3. Biswas, S.; Chowduri, A.; Das, J.; Hosen, Z.; Uddin, R.; Rahaman., S. Literature Review on Pharmacological Potential of Kalanchoe pinnata (Crassulaceae), African Journal of Pharmacy and Pharmacology, 2011. 5(10): 1258-1262.

4. Saputra, T. R; Ngatin, A. Extract of Cocor Bebek (Kalanchoe pinnata) as a Corrosion Inhibitor. Jurnal Bahan Alam Terbarukan. 2017. 6 (2) 112-116

5. Saputra dan Ngatin, 2017, Pengelompokan Golongan Senyawa Ekstrak Semi Polar Cocor Bebek (Kalanchoe pinnata) dan Aktivitasnya Sebagai Inhibitor Korosi, Penelitian Pemula DIPA POLBAN.

6. Saputra, T. R.; Ngatin A. Ekstraksi Daun Cocor Bebek Menggunakan Berbagai Pelarut Organik Sebagai Inhibitor Korosi Pada Lingkungan Asam Klorida. Fullerene Journal of Chemistry. 2019. 4(1): 21-27.

7. Jones, D.A. Principles and Prevention of Corrosion, New York, Macmillan Publishing Company. 1992.

8. Trethewey, K. R.; Chamberlain, J. Korosi, Untuk Mahasiswa dan Rekayasawan, Jakarta, Dramedia Pustaka Utama. 1988.

9. Djaprie, S . Ilmu dan Teknologi Bahan, ed. 5, Jakarta, Erlangga. 1995. 